\title{
Ï̈berfind der Abkürz̧ungen.
}

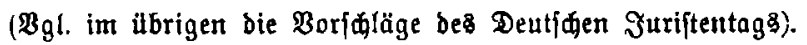

U. A. . . . $=$ Underer $\mathfrak{A}$ nfift.

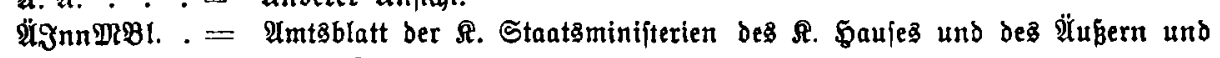

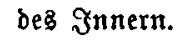

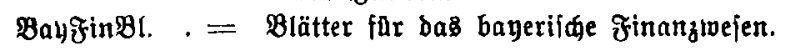

Bay\&em8. . = Bayerifide Bemeindezettung.

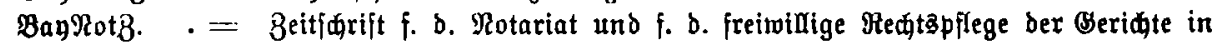
Bayern.

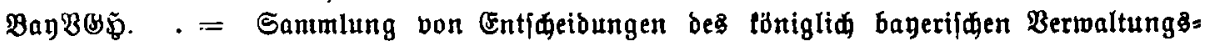
geridtahofä.

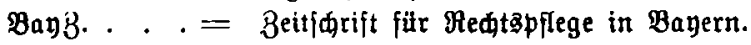

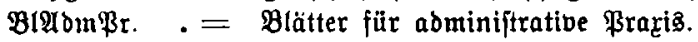

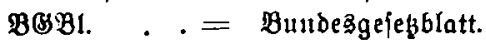

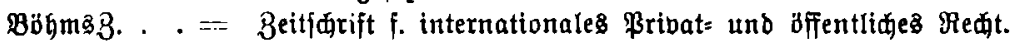

DS3. . . . = Deutíde Juriftenzeitung.

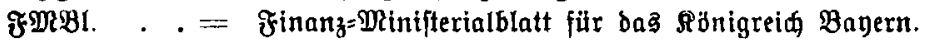

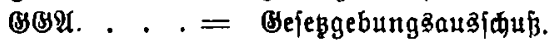

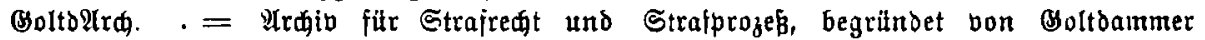
herausgegeben von §. Rogler.

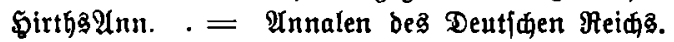

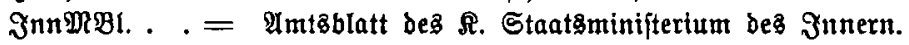

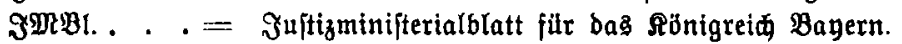

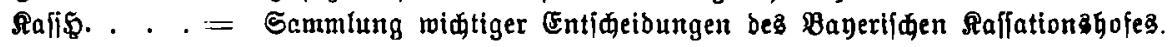

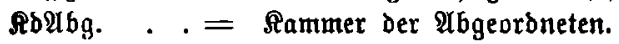

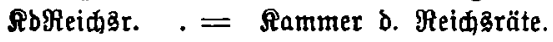

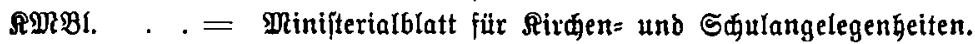

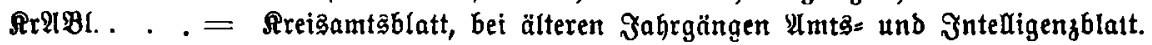

ObSR. . . . = Mitteilungen ber Oberberufungstomniffion in Steuerfadest.

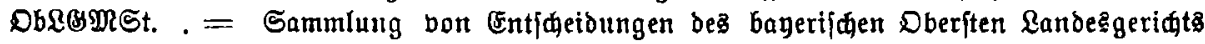
in Straffachen.

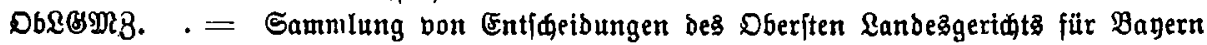
in Segentitänden bes Bivilrechtes und Bivilprozeffeas.

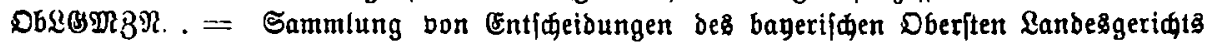
in Bibilfatien, Reue folge.

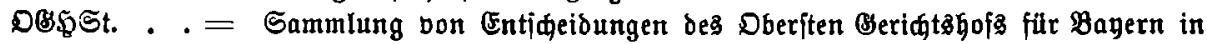
Begenjtänden bez Strafredts und dea Strapprozeffes.

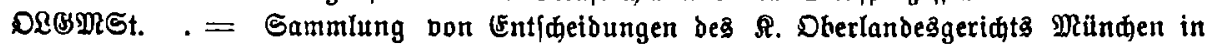
Bregenftänben dez Strafredts und Strafprozefies.

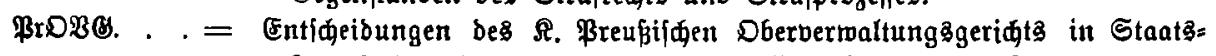

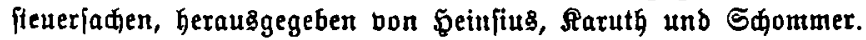

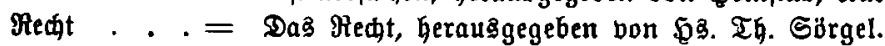

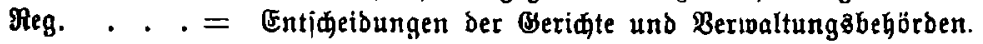




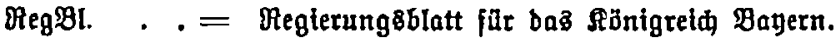

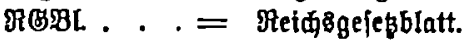

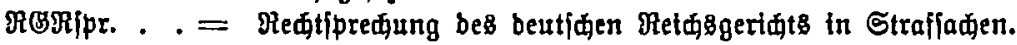

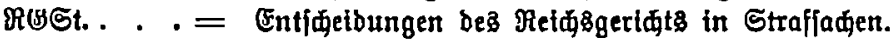

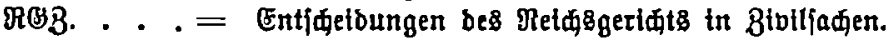

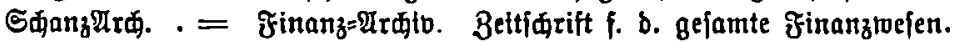

Seuff:I. . . = Seuffert8 Blätter fír Recttaninenbung.

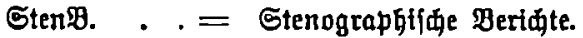

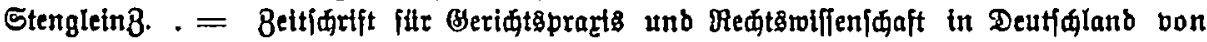
Dt. Stenglein.

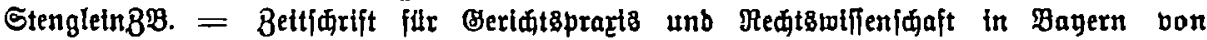
M. Stenglein.

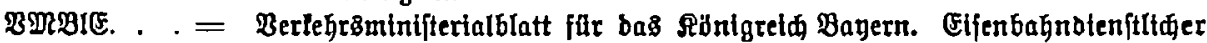
Eeil.

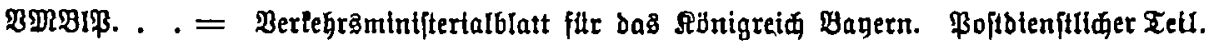

BQI. . . . = Bentralblatt fár bas Deutiøe Reta.

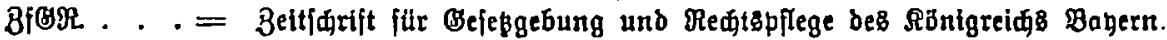

Bollgl. . . = 2 mt8blatt ber Beneralbireltion ber Bäle unb inbirelten Steuern.

8on8. . . . = Bettidrift far 8outwejen unb Betabiteuern.

\section{Nach)träge}

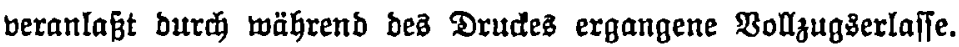

84 5. 298 Intm. 6:

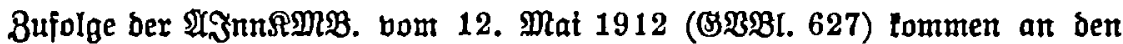
Feiertagen an latbolifăen Drten folgende in Megfall: Mariä Ridutmeß̉, Mariä

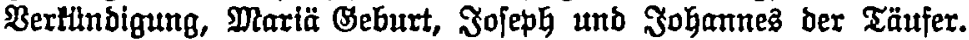

Bu 5. 288 :

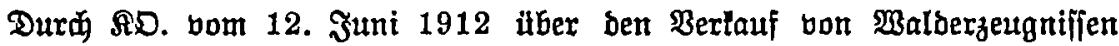

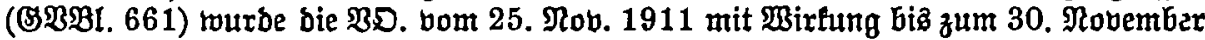

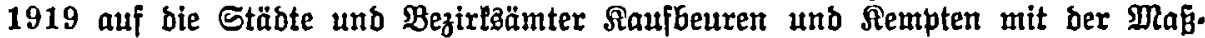

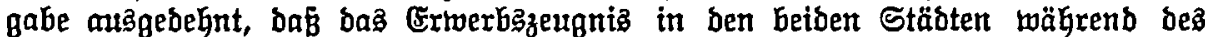

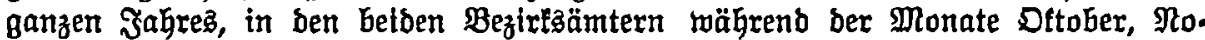
vember und Dezember exforberlifi ijt.

8u ธ. 537:

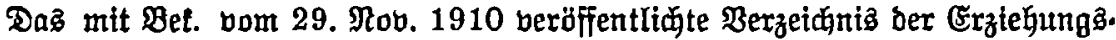

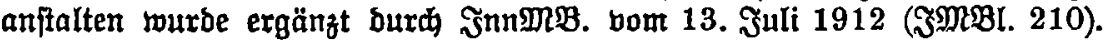

